Hydrol. Earth Syst. Sci. Discuss., 6, 1651-1676, 2009 www.hydrol-earth-syst-sci-discuss.net/6/1651/2009/

(C) Author(s) 2009. This work is distributed under the Creative Commons Attribution 3.0 License.
Hydrology and Earth System Sciences Discussions

Papers published in Hydrology and Earth System Sciences Discussions are under open-access review for the journal Hydrology and Earth System Sciences

\title{
Improvement of surface albedo parameterization within a regional climate model (RegCM3)
}

\section{Y. Bao and S. Lü}

Cold and Arid Regions Environmental and Engineering Research Institute, Chinese Academy of Sciences, 730000 Lanzhou, China

Received: 10 January 2009 - Accepted: 12 January 2009 - Published: 4 March 2009

Correspondence to: Y. Bao (byan @Izb.ac.cn)

Published by Copernicus Publications on behalf of the European Geosciences Union.

\section{HESSD}

$6,1651-1676,2009$

Improvement of surface albedo parameterization

Y. Bao and S. Lü

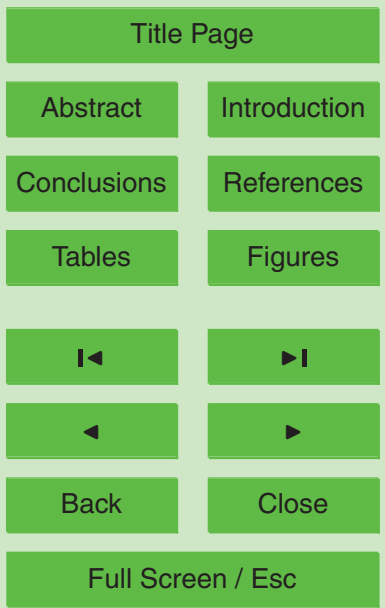

Printer-friendly Version

Interactive Discussion 


\section{Abstract}

A parameterization for calculating surface albedo of Solar Zenith Angel (SZA) dependence with coefficient for each vegetation type determined on the Moderate Resolution Imaging Spectro-radiometer (MODIS) reformed by the Bidirectional Reflectance Dis5 tribution Function (BRDF) is incorporated within the latest Abdus Salam International Centre for Theoretical Physics (ICTP) Regional Climate Model (RegCM3), and evaluated with a high resolution one-way nesting simulation in China using the Climate Research Unit (CRU) data and the observations from the Field Experiment on Interaction between Land and Atmosphere in Arid Region of Northwest China (NWC-ALIEX). The performance of the SZA method modeling surface characteristic is investigated. Results indicate, RegCM with SZA method (RCM_SZA) considerably improve the cold bias of original RegCM (RCM_ORI) in air surface temperature in East Asia with 1.2 degree increased in summer due to the lower albedo produced by SZA method which makes more solar radiation absorbed by the surface and used for heating the atmosphere 15 near to the surface. The simulated diurnal cycle of ground temperature conforms fairly well to the observation in the nesting simulation in Northwest China, especially during the noon time when the SZA has the lowest value. However, the modification can not obviously affect the East Asia summer monsoon precipitation simulation although RCM SZA produce more evapo-transpiration in surface with more than $2 \mathrm{Wm}^{-2}$ increases in simulated latent heat fluxes both in East Asia and in Northwest China compared to RCM_ORI.

\section{Introduction}

Land surface albedo represents the proportion of the incoming radiative flux reflected by the surface. It is a very important land surface parameter in physical climate system which controls directly the partition of radiation energy in surface, thus affects the surface temperature and evapo-transpiration, consequently, affects the modeled atmo-
HESSD

6, 1651-1676, 2009

Improvement of surface albedo parameterization

Y. Bao and S. Lü

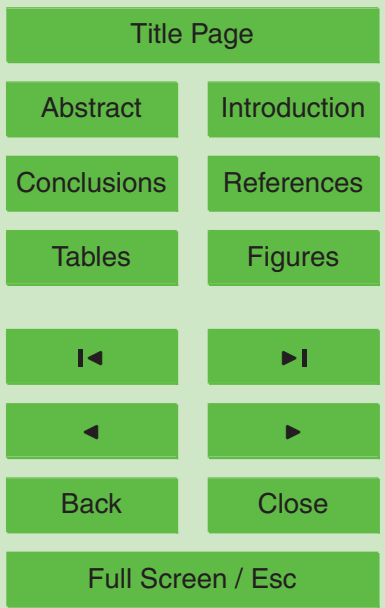

Printer-friendly Version

Interactive Discussion 
sphere condition, that, in turn, affects the basic land surface conditions and the largeor meso- scale flux transportation between the atmosphere near to the surface and boundary layer. Several studies have shown that surface albedo has a negative effect on moisture flux convergences and rainfall, and desertification results generally in 5 droughts by a positive feedback between land and atmosphere caused by high surface albedo (Charney et al., 1975; Chervin, 1979; Sud and Fennessy, 1982; Sud and Molod, 1988; Xue and Shukla, 1993; Dirmeyer and Shukla, 1996; Knorr et al., 2001). It has long been recognized that accurate surface albedo information is essential for weather forecasting and climate modeling.

10 Errors in the specification of surface albedos in numerical models will cause great deviations in surface temperature such as reported in the NCAR Community Climate Model Version 3 (CCM3) by Bonan (1998). High soil albedos in desert in the Saharan region in this model caused temperatures that are several degrees (up to 5 degree) colder than the observations throughout the year. Recent studies show that the previously assumed albedo for the boreal forest in winter, which is set as the National Centers for Environmental Prediction model (NCEP) (Kalnay et al., 1996) and the European Centre for Medium-Range Weather Forecasts model (ECMWF report, 1993), can be more than five times higher than actual magnitudes, and simulations using such magnitudes underestimate daily winter temperatures over the boreal region by 10-15 degree (Betts and Ball, 1997; Baldocchi et al., 2000). Using an energy balance climate model, Otterman et al. (1984) conclude that the lower albedo of high-latitude forests in winter increases surface temperature at $65^{\circ} \mathrm{N}$ by 5 degree. In regional climate model RegCM3, the too high surface albedo likely contributes to the too much energy loss in the atmosphere which partly induces the cold bias in winter in East Asia 25 (Steiner et al., 2005). For some special underlying surface like bare soil of desert in arid areas, the surface characterized by relative high albedo that is strongly dependent on the SZA but still assumed to be independent on SZA and even with uniform value in most land surface models, the uncertainty and deviation from inaccuracy albedo parameters simulated by off-line land surface models make several degree cold bias in
HESSD

6, 1651-1676, 2009

Improvement of surface albedo parameterization

Y. Bao and S. Lü

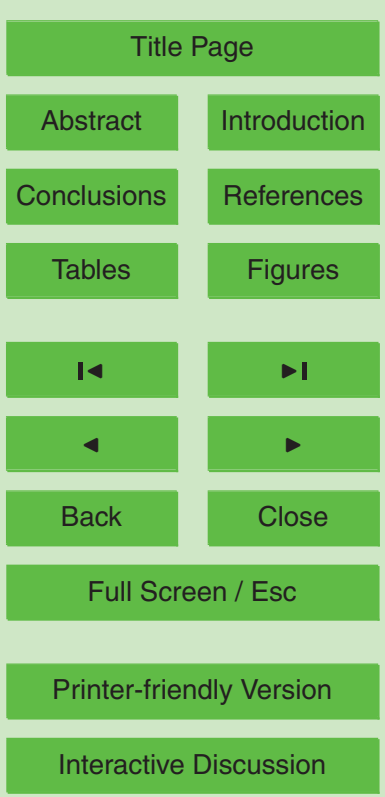

Interactive Discussion 
ground temperature e in summer (Wang et al., 2005; Bao et al., 2007, 2008).

According to the previous research from RegCM3, the model tends to simulate the cold bias of several degrees during winter. Besides the general reasons that the excessive high level cloudiness produced by model and possibly the lack of urban heating in 5 local areas (Giorgi et al., 1999), and the formulation of snow processes in BATS which depends on snow albedo and fractional cover descriptions that may include significant factors of uncertainty maybe contributing to the variance of temperature in winter (Steiner et al., 2005), the simulated surface albedo bias from the coupled land surface model BATS is considered to be one of the other possible factor. Wei et al. (2001) compared the albedo of different land surface types produced by BATS with the advanced very high resolution radiometer (AVHRR) data, found the model simulate the higher albedo than AVHRR for all of the vegetation types in range of 0.01 to 0.04 , and demonstrate the highest bias for deserts and semi-desert regions where the bias is increased beyond 0.05 , as well as the regions with winter snow.

15 The surface albedo is strongly dependent on the SZA and the three-dimensional (3D) structure of vegetation canopy (Yang, et al., 2001; Schaaf et al., 2002). In this paper, a newly-developed parameterization for computing the surface albedo of SZA dependence with coefficients for each vegetation type determined on MODIS data reformed by the BRDF method, which is specially developed for weather forecasting and climate modeling (Wang et al., 2005, 2007), is implemented within the latest ICTP RegCM3. The ability of SZA method in representing the regional land surface characteristic and regional climate are investigated. Our purpose of this study is twofold. First, the performance of this SZA method in modeling the surface radiation balance and surface thermal conditions, especially during the summer monsoon period in East Asia needs to be evaluated for future and extensive use, and the improved cold bias in RegCM from SZA simulation are expected; Second, the ability of SZA method representing the ground temperature over desert areas in arid and semi-arid regions in Northwest China is particularly focused on since it is an attempt padding the inaccuracy and uncertainty of land surface parameters due to the few in-situ data available reported by remote

HESSD

6, 1651-1676, 2009

Improvement of surface albedo parameterization

Y. Bao and S. Lü

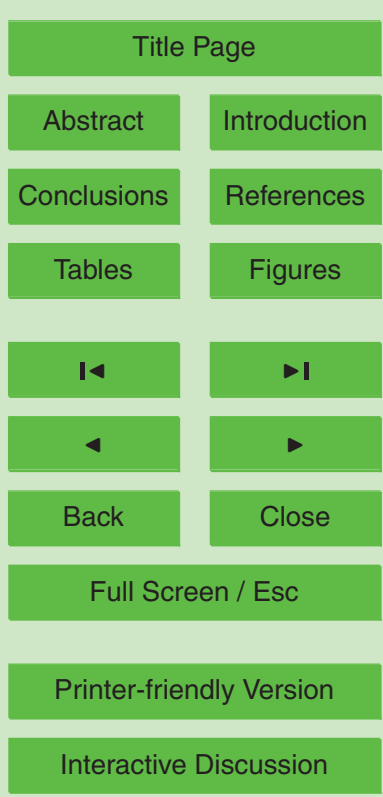

1654 
sensing parameterization. More work should be sampled by this way.

In Sect. 2, the model in this study and the strategy of this experiment as well as the related surface albedo schemes in BATS and SZA method are briefly introduced. The evaluation of SZA method and the modification in RegCM3 are shown in Sect. 3. 5 Finally, a common summary and discussion are presented in the last section.

\section{Experimental design}

\subsection{Model description}

The regional model used here is the latest version of the ICTP RegCM3. This is an upgraded version of the model originally developed by Giorgi et al. (1993a, b) and then im10 proved and discussed by Giorgi and Mearns (1999) and Pal et al. (2007). The dynamic core of the RegCM3 is equivalent to the hydrostatic version of NCAR/Pennsylvania State University meso-scale model MM5 (Grell et al.,1994). The physics parameterizations employed in this simulation include the comprehensive radiative transfer package of the NCAR Community Climate Model, version CCM3 (Kiehl et al., 1996), the nonlocal boundary layer scheme of Holtslag et al. (1990), the latest version of BiosphereAtmosphere Transfer Scheme (BATS, Dickinson et al., 1993), the modified large-scale cloud and precipitation scheme which accounts for the subgrid-scale variability of clouds (Pal et al., 2000).

Just as we mentioned above, the surface physics processes in current model are represented by the final BATS land surface scheme (Dickinson et al., 1993), which is designed to describe the role of vegetation and interactive soil moisture in modifying the surface-atmosphere exchanges of momentum, energy, and water vapor. The soil hydrology calculations include predictive equations for the water content of the surface soil layer, the root zone, and the deep soil layer. These equations account for precipitation, snowmelt, evapor-transpiration, surface runoff, and diffusive exchange of water between soil layers. Snow depth is also prognostically calculated from snowfall,

HESSD

6, 1651-1676, 2009

Improvement of surface albedo parameterization

Y. Bao and S. Lü

Title Page

Abstract Introduction

Conclusions

Tables

References

Figures

14

4

Back

Close

Printer-friendly Version

Interactive Discussion 
snowmelt, and sublimation.

\subsection{Surface albedo parameterizations}

HESSD

In land surface model BATS, the albedo of bare soil is calculated by formula

$\alpha=\alpha_{\text {sat }}+\Delta \alpha_{g}\left(S_{s w}\right)$

5 where $\alpha_{\text {sat }}$ is the albedo of a saturated soil, $S_{s w}$ is the ratio of surface soil water content, and an increase of albedo due to dryness of surface soil within the wavelength $\lambda<0.7 \mu \mathrm{m}$ can be calculated by formula (2):

$\Delta \alpha_{g}\left(S_{s w}\right)=0.01\left(11-40 S_{s w} / Z_{u}\right)>0$

where $Z_{u}$ is the upper soil layer depth. This formula is chosen so that albedos range in a nonlinear fashion between the saturated and dry magnitudes. The magnitude of Ssw becomes very small $(0.025 \mathrm{~m})$ before and when the soil albedo shows a significant increase. Moisture is retained around the soil grains until $80 \%$ dryness occurs. The diffuse albedo is simply assumed to be synonymous with direct albedo, and soil albedos within $\lambda>0.7 \mu \mathrm{m}$ are twice as much as those within $\lambda<0.7 \mu \mathrm{m}$.

For vegetation, BATS uses prescribed values for vegetation albedo for both shortand longwave components based on the BATS land cover types.

In the research of Wang et al. $(2005,2007)$, the direct albedo normalized by its magnitude at $60^{\circ} \mathrm{SZA}$ can be adequately represented by a simple two-parameter formula reformulated from the MODIS/BRDF algorithm (Ranson, et al., 1991; Schaaf et al., 2002):

$\alpha(\theta)=\alpha_{r} \times\left(1+B_{1} *\left(g_{1}(\theta)-g_{1}\left(60^{\circ}\right)\right)+B_{2} *\left(g_{2}(\theta)-g_{2}\left(60^{\circ}\right)\right)\right)$

$\alpha_{r}$ has a clear physical meaning as the albedo at $60^{\circ} \mathrm{SZA}$, and its magnitude depends on season and location; $\theta$ is solar zenith angle. $B_{1}$ and $B_{2}$ are respectively the ratio of the volumetric and geometric parameters which can be obtained from the

Improvement of surface albedo parameterization

Y. Bao and S. Lü

Title Page

Abstract Introduction

Conclusions

Tables References Figures

14

4

Back

Close

Full Screen / Esc

Printer-friendly Version

Interactive Discussion 
MODIS BRDF data. In formula (3), the same $B_{1}$ (or $B_{2}$ ) is used for the visible (VIS) band (0.3-0.7 $\mu \mathrm{m})$ and near-infrared (NIR) band $(0.7-5 \mu \mathrm{m})$ for the same vegetation type. Also, $B_{1}$ and $B_{2}$ are assumed to be dependent on vegetation type only. With this characteristic, the formula is very convenient for use in numerical weather prediction 5 (NWP) since in most of which, the surface parameters only depend on the land type classification. In Wang et al.'s research, the averages over 40 pixels for each vegetation type and 30 pixels for desert of $B_{1}$ and $B_{2}$ are provided in Wang et al's research. (Wang et al., 2005, 2007). The functions $g_{1}$ and $g_{2}$ are from the MODIS algorithm (Schaaf and Coauthors, 2002):

$$
\begin{aligned}
& g_{1}(\theta)=-0.007574-0.070987 \theta^{2}+0.307588 \theta^{3} \\
& g_{2}(\theta)=-1.284909-0.166314 \theta^{2}+0.04184 \theta^{3}
\end{aligned}
$$

Diffuse albedo is the integral of all SZAs with the weight of $\cos \theta$.

\subsection{Experimental design}

The exchange of land-atmosphere flux is a sub-grid scale process (Sun, 2006). To get the sub-grid land surface flux and high-resolution surface climate, the one-way nesting method is used in this paper. The mother domain encompasses the most of China at $60 \mathrm{~km}$ grid spacing with $128 \times 96$ grids, with the full simulation period ranging from 1 May 1999 to 1 September 2001. The models are driven by ECMWF data (Technical Attachment, 1993). Two experiments are implemented in mother domain, one is using original RegCM3 named RCM_ORI, and the other is using RegCM3 with SZA scheme named RCM_SZA. To allow for a one-month spinup time period, we analyze the results from 1 June 1999 to 1 September 2001. Before running the model, some landuse modifications have been done, with the "Irrigated Crop" points in the whole domain replaced by the "Crop/mixed farming" since they induce the too wet soil conditions in RegCM simulation which results in the several degrees' cold bias in air surface temperature over East Asia (Personal conversation with Professor Giorgi from ICTP). Figure 1 show the selected domain and landuse distribution.

HESSD

6, 1651-1676, 2009

Improvement of surface albedo parameterization

Y. Bao and S. Lü

Title Page

Abstract Introduction

Conclusions

Tables References Figures

14 $\rightarrow$

4

Back

Close

Full Screen / Esc

Printer-friendly Version

Interactive Discussion 
For the nested domain, we focus on a relatively homogeneous and even area in Badain Jaran Desert centered at Dunhuang site $\left(40^{\circ} 10^{\prime} \mathrm{N}, 93^{\circ} 31^{\prime} \mathrm{E}\right)$ in Northwest China, running the model at $20 \mathrm{~km}$ grid spacing with $136 \times 70$ grids from 1 May 1999 through 1 March 2001 (Fig. 1). Also there are two experiments incorporated in the ex5 periments which are respectively driven by the output from RCM_ORI and RCM_SZA. The former one is the benchmark experiment named NRCM_ORI, the latter one is the compared experiment with the newly-developed SZA scheme incorporated named NRCM_SZA. The whole 15-month simulations are used for analysis. Figure 1 show the topography and landuse distribution of the selected domain.

\subsection{Evaluating strategy}

The monthly surface air temperature, minimal, maximal air temperature and precipitation of Climate Research Unit (CRU) with $0.5 \times 0.5$ grid resolution are used as the observations to validate the basic performances of model. Research indicate that the precipitation of CRU data has a high reliability as the meteorological station observacorrelation coefficient between the seasonal precipitation and the station observations of 160 stations being 0.93 (Wen et al., 2006). The surface energy budget components and ground temperature of Dunhuang in-situ data of NWC-ALIEX from 1 June 2000 to 1 March 2001 are used to examine the simulations in nested domain. The measuring 20 instruments and accuracies of the data are described in Zhang and Huang (2002) and Zhang et al. (2004).

\section{Simulated results}

In this section, we present a general analysis of the mother domain simulation and nesting domain simulation. In mother domain, the abilities of model representing the
HESSD

$6,1651-1676,2009$

Improvement of surface albedo parameterization

Y. Bao and S. Lü

Title Page

Abstract Introduction

Conclusions

Tables References

Figures

14 $\rightarrow$

4

Back

Close

Full Screen / Esc

Printer-friendly Version

Interactive Discussion 
surface characteristic over desert is engaged. As mentioned before, the nested domain is a relatively homogeneous desert which centers at the Dunhuang sites, only the results from 1 December 1999 to 1 March 2001 are represented in this paper.

We begin our analysis from simulated surface albedo with different schemes as the 5 basic analysis. Figure 2 show the simulated June-July-August (JJA) averaged albedo of the full simulated period. It is found that RCM_ORI and RCM_SZA produce the generally similar albedo spatial distribution since the albedo calculation in RegCM significantly depend on geographic location and the landuse/land cover distribution associated with the snow fraction over the soil and vegetation, and the same landuse data 10 are used in the two experiments. The results indicate the high albedo distribute in North China and the Tibetan Plateau because of the high geographical latitudes and the low vegetation fraction, also the large-area snow cover in high evaluations. In RCM_ORI run, most the values in those places are more than 0.28 , and over 0.4 in some places in Tibetan Plateau, which are greater than the in-situ data in some typical stations at 15 Dunhuang Gobi (Zhang et al., 2004), Huayin Gobi (Hu et al., 1999), Jinta Gobi (Bao et al., 2007, 2008) and Namucuo on Tibetan Pleatau (Wang et al., 2004) in Northwest China, as well as MODIS and AVHRR satellite remote sensing values of albedo (Xu and Lin, 2002; Wei et al., 2001) (See Table 1). In the East and South China, most of the albedo is lower than 0.2 because of the high vegetation fraction in growing seasons and the high soil moisture induced by the monsoon precipitation in summer season. Compared to RCM_ORI simulation, RCM_SZA substantially simulates the lower albedo with the typically 0.01 to 0.02 decrease in most of China, especially for the places in South and East Asia with the Crop/mixed farming distributed, and the Ice cap/glacier regions in Northeast China (Fig. 2b, c). Large discrepancies also exists in Northwest

China where there are the large-scale desert and semi-desert regions distributed. According to the research of Wei et al. (2001), in desert and semi-desert regions for snow-free surface, BATS and LSM respectively simulate 0.07 and 0.03 higher albedo than AVHRR albedo data, which seems to contribute the several degrees cold bias in ground temperature over desert in CCM3 model (It takes LSM as the land surface
HESSD

$6,1651-1676,2009$

Improvement of surface albedo parameterization

Y. Bao and S. Lü

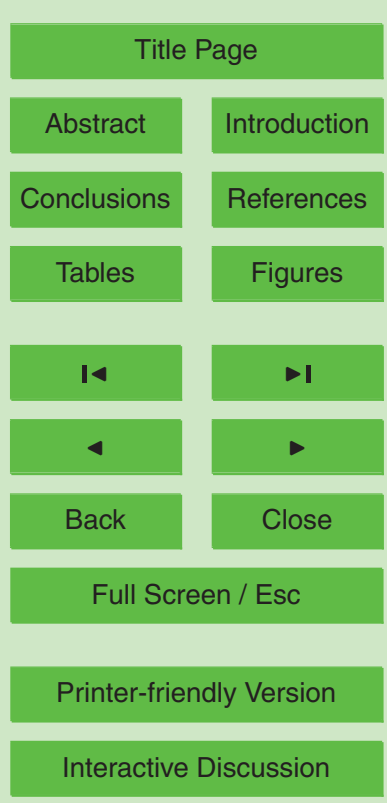


sub-model), especially in North Africa where in LSM the albedo is adjusted upward by 0.1 compared to the other deserts in the world. The similar decreases happen to the albedo simulations in other seasons like spring and autumn but so obvious as that in summer (not shown).

5 The relevant surface absorbed solar radiations are shown in Fig. 3. Both RCM_ORI and RCM_SZA runs expose that the more solar radiation absorbed by surface in Southeast China than other places due to the lower albedo in vegetation there (Fig. $3 a, 3 b$ ). Compared to RCM_ORI, typically $10-15 \mathrm{Wm}^{-2}$ additional solar radiation is received by the surface in RCM_SZA simulation in summer, with the greatest increased radiation 10 more than $30 \mathrm{Wm}^{-2}$ in some places in the East and North China (Fig. 3c), which is consistent with the relatively more decreased albedo values there that make more incident solar radiation come into the surface (Fig. 2a, b).

In East Asia, on an average, RCM_ORI and RCM_SZA receive respectively 233.44 and $242.87 \mathrm{Wm}^{-2}$ incident solar radiation in surface in JJA. They are smaller than 15 the observations during the period of 1984-1990 based on global 2.5 degree resolution data derived from the International Satellite Cloud Climatology Project (ISCCP) (Bishop and Rossow, 1991). RCM_SZA absorbs approximately $13 \mathrm{Wm}^{-2}$ solar radiation more than RCM_ORI runs with $9 \mathrm{Wm}^{-2}$ additional incoming solar radiation incorporated which accounts for 69 percent in the increased energy absorbed by surface, with other 31 percentage coming from the variety of surface albedo (Table 1). The increase of solar radiation in RCM_SZA can be explained by the decrease in the cloud liquid water amount in this model. Compared to RCM_ORI, RCM_SZA simulates decreased $2.2 \mathrm{gm}^{-2}$ liquid water below $850 \mathrm{hpa}$ in East Asia which accounts for 10 percent of total liquid water amount. The same increase happens to the longwave cooling (Fig. 3d, $25 \mathrm{e}, \mathrm{f}$ ), there is extra upward $5 \mathrm{Wm}^{-2}$ longwave radiation used for heating the air near to surface, as well as the sensible heat flux $\left(4.7 \mathrm{Wm}^{-2}\right.$ increased) and latent heat flux (2.6 $\mathrm{Wm}^{-2}$ increased).

While in Northwest China where there is widely-distributed desert area and precipitation seldom occurs in summer seasons, the incoming solar radiation contributes little
HESSD

$6,1651-1676,2009$

Improvement of surface albedo parameterization

Y. Bao and S. Lü

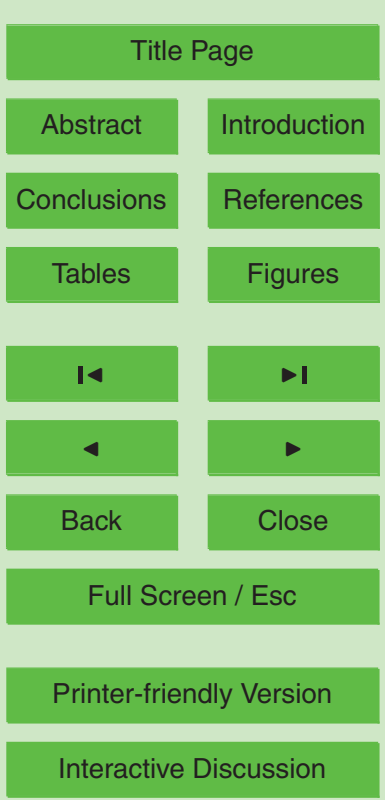


for the increased radiation flux, indicating the lower albedo in RCM_SZA are responsible for the extra about $6 \mathrm{Wm}^{-2}$ solar radiation absorbed by surface. There is still $4.9 \mathrm{Wm}^{-2}$ longwave radiation increased which is used for heating the atmosphere, but the surface sensible heat flux in Northwest China has a small change although there is 5 still about $2 \mathrm{Wm}^{-2}$ increased in simulated latend heat flux.

An investigation of the energy partitioning at the surface can lend some insight into the differences between the surface temperature simulations in the two schemes. Figure 4 illustrate the seasonal cycle of energy budget for five components, the incoming solar radiation, the absorbed solar radiation, longwave cooling, sensible heat flux 10 and latent heat flux from RCM_ORI and RCM_SZA runs respectively in East Asia and Northwest China (Note that positive values for sensible and latent heat indicate a loss of energy from the land surface to the atmosphere).

In East Asia, typically, the annual surface absorbed solar reaches a minimum in January and a maximum in July. The onset of the East Asia monsoon causes this relatively 15 lower surface solar radiation in June during the summer because the large cloud liquid water amounts reduce the amount of solar radiation that reaches the surface (Fig. 4a). On the contrary, the longwave cooling reaches a minimu, in July when there is the greatest monsoon precipitation and a maximum in early winter months (like October and November). Also RCM_ORI and RCM_SZA partition the absorbed radiation into the sensible heat flux and latent heat flux with quite similar. The seasonal cycles of these values include a minimal sensible heat flux in the early winter months and a maximal in the late spring (like March to May). The latent heat flux peak lags the sensible heat flux by a few months. Due to the onset of monsoon season. Both in winter and summer seasons the latent heat flux is the big partition in the total energy which 25 accounts for the one half of the general surface energy in cold seasons. During the whole year, RCM_SZA simulates more surface absorbed radiation and latent heat flux most of which are used for heating and moistening the air near to the surface although the increased energy are different in individual seasons.

In Northwest China (not shown), all the components have the very smooth reserve
HESSD

$6,1651-1676,2009$

Improvement of surface albedo parameterization

Y. Bao and S. Lü

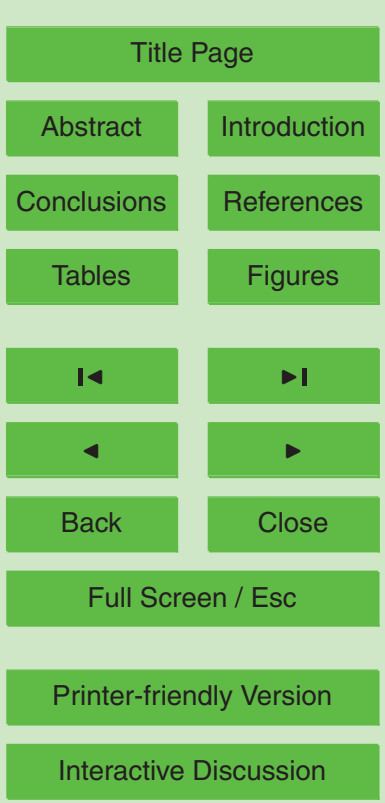


parabola curves, with the maximum in June or July and minimum in winter seasons because the few precipitation in desert during summer, and their little effect on solar absorbance by the surface and division in different components. As a comparison, the incident radiation from RCM_SZA is much higher than that from RCM_ORI due to the 5 rare precipitation, $(50 \mathrm{~mm} / \mathrm{y}-100 \mathrm{~mm} / \mathrm{y}$ in most of places). Similar to the simulation in East Asia, RCM_SZA simulates more surface absorbed radiation and latent heat flux during the whole year especially in summer seasons although the sensible heat flux covers more than $50 \%$ of the general surface radiation both in cold seasons and in warm seasons in Northwest China, which will feedback the warmer and wetter simu10 lated climate in RCM_SZA.

In Fig. 5 and Table 1, the simulated air surface temperature is compared with observed surface temperature from the $\mathrm{CRU}$ dataset. In summer seasons, the simulated temperature in East Asia is lower than observations by 1 to 3 degrees (Fig. 5a, b, c, e, f) which can be found in many simulations in East Asia with RegCM3 (Giorgi et al., 15 1999; Gao et al., 2006; Pal et al., 2007; Bao et al., 2008) due to the excessive high level cloudiness and possibly the lack of urban heating effects which could have a significant impact in densely populated urban appears of East Asia (Giorgi, 1999). While in the Northwest China, there are positive biases for the high evaluation in mountains with the exception to some deserts possibly due to the un-appropriate parameterization in BATS to handle the snow which depends on snow albedo and fractional cover descriptions that may include significant factors of uncertainty (Steiner et al., 2005). Note the largest positive temperature bias occurs in the mountains in Northwest China when only a small number of reporting stations are available. Regionally, compared to RCM_ORI, RCM_SZA considerably reduce the cold bias in East China (Fig. 5d), with 251.2 degree increase in air surface temperature which are consistent with the additional solar radiation absorption in surface (Table 1). In the desert in Northwest China, the extra absorbed solar radiation also reflects in the surface air surface temperature with the 0.34 degree increased air surface temperature.

We also examined the diurnal difference between daily minimal and maximal tem-
HESSD

$6,1651-1676,2009$

Improvement of surface albedo parameterization

Y. Bao and S. Lü

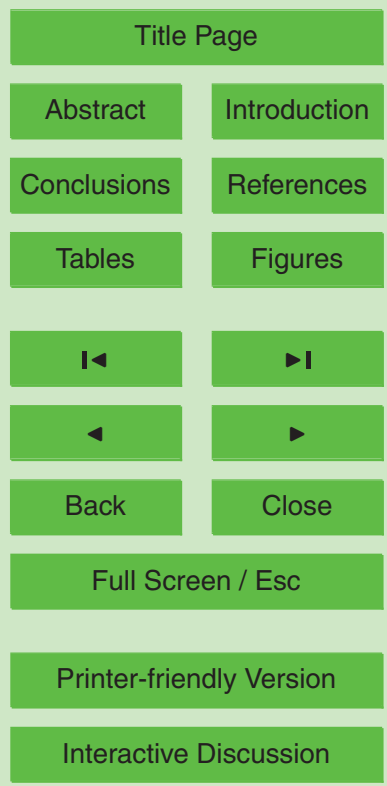


perature the two models, and found the increase of air surface temperature is mainly due to the increase of daily maximal temperature (Fig. 4b). Over the annual simulation in East Asia, the RCM_SZA 0.5 to 1.5 degree higher maximal temperature that is 0.5 degree to 1.5 degree greater than RCM_ORI, and this difference increase to approx5 imately 2 to 2.5 degree in the summer. Both the two models simulate the 1 to 2.5 degree higher daily minimal temperature compared to CRU data, in particular during summer seasons. The similar changes but with smaller range happen to counterparts in Northwest China (not shown). On the whole, compared to simulations of RCM_ORI, the simulations of RCM_SZA show the smaller range of seasonal cycle in temperature, 10 indicating a shift upwards to warmer temperatures over the full diurnal cycle. This could partially explain the similarity between RCM_SZA simulations and observed air surface temperature.

The simulated East Asia summer monsoon precipitation is also evaluated with CRU precipitation (not shown). Beyond our expects, no more precipitation occurs both in 15 East Asia and in Northwest China although there are above $2 \mathrm{~W} \mathrm{~m}^{-2}$ extra latent heat fluxes in RCM_SZA simulations. It is also found in other work about modification the land surface scheme in RegCM (Steiner et al., 2005) Giorgi and Bi's research (2000) has shown that the simulated precipitation exhibits a significant level of variability due solely to the nonlinearities in the internal dynamics and physics of the model. The possible reason of this also could be that the large bias in simulated precipitation in China with RegCM3 (several to tens mm/day minus bias in East Asia) which covers the improvements induced in RCM_SZA simulation.

The observed and simulated diurnal energy budget radiation is shown in Fig. 6 . It is observed both the simulated incoming solar radiations and absorbed solar radiations

25 from NRCM_ORI and NRCM_SZA are greater than the observations, and the differences between observations and models are increasing after the noontime (Fig. 6a). There is slight increase in absorbed solar radiation but much more decrease in longwave cooling and sensible heat flux from NRCM_SZA compared with the simulations from NRCM_SZA, indicating more energy are stored in the ground to heat the surface
HESSD

$6,1651-1676,2009$

Improvement of surface albedo parameterization

Y. Bao and S. Lü

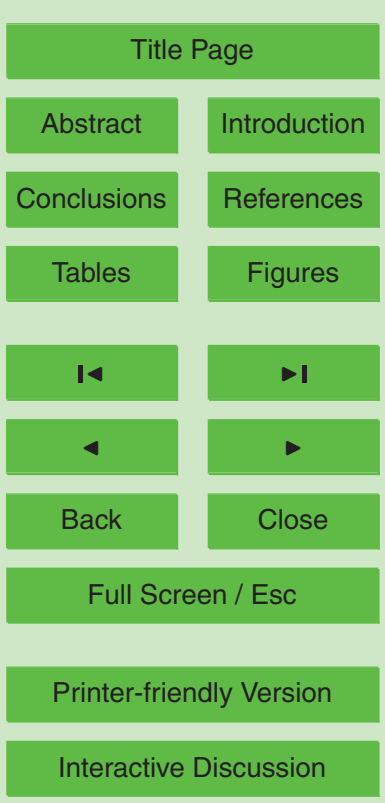


and soil. As the result, the simulated ground temperature from NRCM_SZA has a considerable improvement compared to that from RCM_ORI, especially at the noontime (Fig. 6b). For the seasonal cycle, the simulated incoming solar radiation and absorbed solar radiation from NRCM_SZA decrease but more agreeable with the observations 5 compared to the simulations from NRCM_ORI. Beyond our expectation (Fig. 6c), while the simulated ground temperature from the two model are very similar in most seasons which are far beyond the observations except during the winter months when NRCM_SZA simulates the more close ground temperature to observation (Fig. $6 \mathrm{~d}$ ). It seems the modified albedo scheme cannot perform well on long-term simulation.

\section{Summary and discussions}

In this study, a modified SZA method which considers the effect of SZA on surface albedo developed based on the MODIS/BRDF and in-situ data is newly-implemented in ICTP RegCM3 to improve the modeled cold bias in China. The performance of this method in land modeling is evaluated with a one-way nesting simulation in China and a 15 small desert in arid region in Northwest China using the observed data and in-situ data from the Field Experiment (NWC-ALIEX) in Northwest China. The impacts of the SZA method on surface energy budget and surface thermal conditions are investigated.

Results indicate, in the mother domain, RCM_SZA simulates the lower albedo than RCM_ORI in most of China which induce to more solar radiation absorbed by the sur20 face and used for heating the atmosphere near the surface. As a result, the simulated air surface temperature has a considerable improvement in RCM_SZA in JJA in East Asia. There is 1.2 degree increase in simulated air surface temperature which mainly due to the additional incoming solar radiation. While in Northwest China, the simulation of RCM_SZA has a slight increase in the air surface temperature although RCM_ORI

lated the RCM_ORI simulations. For the whole year, both the minimal and maximal air temper-
HESSD

$6,1651-1676,2009$

Improvement of surface albedo parameterization

Y. Bao and S. Lü

Title Page

Abstract

Introduction

Conclusions

Tables

References

Figures

14

$\rightarrow$

4

Back

Close

Full Screen / Esc

Printer-friendly Version

Interactive Discussion 
ature increase in RCM_SZA indicate a shift upwards to warmer temperatures over the full diurnal cycle. However, the simulated precipitation distributions in East Asia and Northwest China have ignorable changes although there are above $2 \mathrm{Wm}^{-2}$ extra latent heat fluxes in RCM_SZA simulations. Besides the reason provided by Giorgi and $5 \mathrm{Bi}(2000)$ that simulated precipitation exhibits a significant level of variability due solely to the nonlinearities in the internal dynamics and physics of the model, another possible reason also could be that the large bias in original RegCM3 which covers the improvements from SZA method in RCM_SZA.

At Dunhuang Gobi site in nesting domain simulations, RCM_SZA also displays the 10 remarkable improvement in ground temperature simulations, in particular during the noontime due to the slightly increasing absorbed solar radiation and decreased longwave cooling which reduce to more energy stored in the surface and soil heating them. While the modification in NRCM_SZA seems to have small effect on simulated seasonal cycle in energy budget components and ground temperature on long-term simulations.

15 The reason is not clear.

Albedo calculation with SZA method is severely dependable on the Landuse/Land cover used in the model. In this work, we only do simple modification about the BATS landuse classifications, more details about landuse (include the more accurate landuse classification and dynamical vegetation information) are needed for the research. Also, we have not shown many details of the simulation in winter because the improvement is not so obvious as that in summer since the SZA method is not involved in snow surface, and we use the same way for snow processing in albeo parameterization within RCM_ORI and RCM_SZA . In fact, the way handling the snow albedo is very important for land surface energy and surface thermal condition, as well as the water

flux transportation between soil layers in winter (Giorgi et al., 2003; Steiner et al., 2005), which possibly reduce to the partly warm bias in RegCM3 in high latitude regions and cold regions. More details about snow should be considered in future land surface model and climate model.

We also have seen, simply "tuning" surface albedos to obtain correct surface temper-
HESSD

$6,1651-1676,2009$

Improvement of surface albedo parameterization

Y. Bao and S. Lü

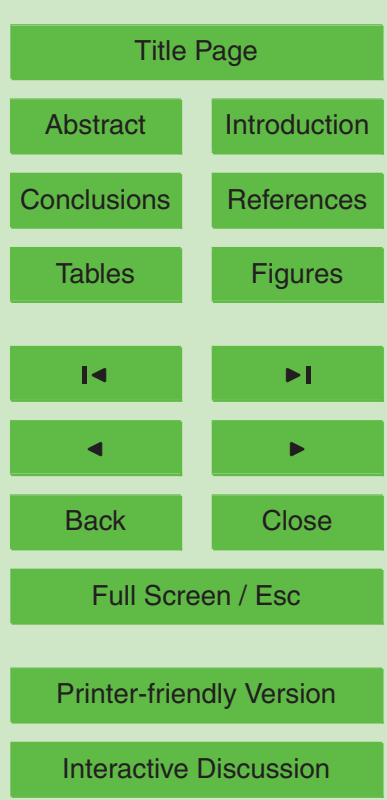


atures may obscured efficiencies in the representation of physical processes within the land surface model and in its coupling to the atmospheric boundary layer. The satellite remote sensing technique provides a wealth of data to describe the land surface condition with a relatively higher resolution, especially the dynamical information which 5 can be useful as a measure of the spatial heterogeneity of the surface and to constrain and improve the land boundary conditions in other ways. It is necessary to incorporate more information from satellite observed data in future land surface parameters (like landuse/land cover, the updated albedo and soil moisture ) and parameterizations.

Acknowledgements. The work was co-supported by the National Natural Science Foundation of China (No.40805042), West Light Foundation of the Chinese Academy of Sciences (CAS) "Numerical simulations of impacts of land surface processes on regional climate in arid region" , Knowledge Innovation Project of the Chinese Academy of Sciences (No. KZCX2-YW-220), and special fund for basic research profession project (No. BROP200712) of Institute of Plateau Meteorology, Chengdu, China Meteorological Administration (CMA). RegCM3 is made publicly dedication and hard work. The authors want to express our thanks to Academician Ronghui Huang from Institute of Atmospheric Physics, Chinese Academy of Science who support the Dunhuang in situ data for the research. We are also very grateful to Professor Giorgi Filippo from International Centre for Theoretical Physics (ICTP) in Italy for his meaningful suggestions

\section{References}

Baldocci, D., Kellliher, F. M., Black, T. A., and Jarvis, P. G.: Climate and vegetation controls on boreal zone energy exchange, Global Change Biol., 6 (Suppl.), 69-83, 2000.

Betts, A. K. and Ball, J. H.: Albedo over the boreal forest. J. Geophys. Res., 102(D24), 2890128910, 1997.

Briegleb, B. P., Minnis, P., Ramanmthan, V., and Harrison, E.: Comparison of regional clear sky albedos inferred from satellite observations and model calculations, J. Clim. Appl. Meteorol., 25, 214-226, 1986.

HESSD

6, 1651-1676, 2009

Improvement of surface albedo parameterization

Y. Bao and S. Lü

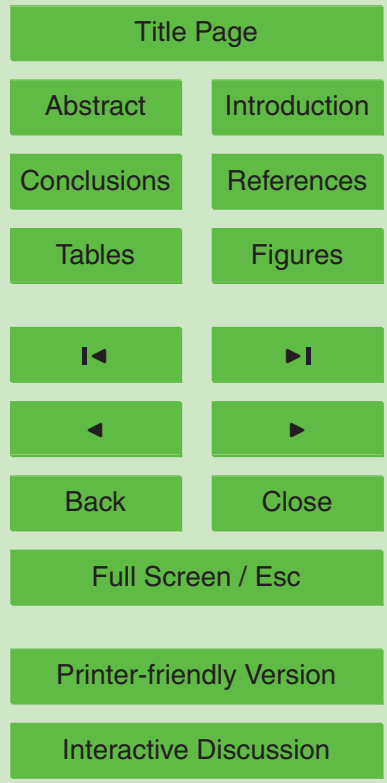

Interactive Discussion 
Dickinson, R. E. and Kenney P. J.: Biosphere atmosphere transfer scheme (BATS) for the NCAR Community Climate Model National Center for atmospheric research, Boulder, CO, USA, Teth. Note Tn-275+STR, 12-51, 1986.

ECMWF Technical Attachment: The description of the ECMWF/WCRP Level III-A global atmospheric data archive. European Centre for Medium Range Weather Forecasts, Reading, UK, 1993.

Giorgi, F., Bao, Y., Bi, X., and Tompkins, A.: Coupling and testing the Tiedtke Convective Parameterization Scheme within the Regional Climate Model (RegCM3): Part I: Summer monsoon climate over East Asia, finished.

10 Giorgi, F., Francisco, R., and Pal, J.: Effects of a subgrid-scale topography and landuse on the simulation of surface climate and hydrology, Part I: Effects of temperature and water vapor disaggregation, Am. Meteor. Soc., 4, 317-332, 2003.

Giorgi, F., Marinucci, M. R., and Bates G. T.: Development of a second generation regional climate model(RegCM2) Partl.Boundary-layer and radiative transfer processes, Mon. Weather

15 Rev., 121, 2794-2813, 1993a.

Gao, X., Xu, Y., and Zhao, Z.: On the role of resolution and topography in the simulation of East Asia precipitation, Theor. Appl. Climatol., 86, 173-185, 2006.

Henderson-Sellers, A.: The project for inter-comparison of land-surface parameterization schemes, B. Am. Meteorol. Soc., 74, 1335-1348, 1993.

20 Idso, S. B., Jackson, R. D., Reginato, R. J.,Kimbal, B. A., and Nakayama, F. S.: The dependence of bare soil albedo on soil water content, J. Appl. Meteorol., 14, 109-113, 1975.

Jin, Y., Schaaf, C. B., Woodcock, C. E., Gao, F., Li, X., Strahler, A. H., Lucht, W., and Liang, S.: Consistency of MODIS surface bidirectional reflectance distribution function and albedo retrievals: 2. Validation, J. Geophys. Res., 108(D5), 4159, doi:10.1029/2002JD002804, 2003.

Kalnay, E. and Coauthors: The NCEP/NCAR 40-year reanalysis project, B. Am. Meteorol. Soc., 77, 437-471, 1994.

Kimes, D. S.: Dynamics of directional reflectance factor distributions for vegetation canopies, Appl. Opt., 22, 1364-1372, 1983.

Minnis, P., Mayor, S., Simth Jr., W. L., and Yong, D. F.: Asymmetry in the diurnal variation of surface albedo. IEEE .T. Geosci. Remote., 35, 879-891,1997.

Monteith, J. and Szeice, G.: The radiation balance of bare soil and vegetation, Q. J. Roy. Meteor. Soc., 87, 159-1701, 1991.

Otterman, J., Chou, M.-D., and Arking, A.: Effects of non-tropical forest cover on climate, J.
HESSD

$6,1651-1676,2009$

Improvement of

surface albedo

parameterization

Y. Bao and S. Lü

Title Page

Abstract

Introduction

Conclusions

References

Tables

Figures

14

$\rightarrow$

4

Back

Close

Full Screen / Esc

Printer-friendly Version

Interactive Discussion 
Clim. Appl. Meteorol., 23, 762-767, 1984.

Pal, G. S., Giorgi, F., Bi, X., Elguindi, N., Solmon, F., Gao, X., Ashfaq, M., Francisco, R., Bell, J., Diffenbaugh, N., Sloan ,L., Striner, A., Winter, J., and Zakery, A.: Regional climate modeling for the developing World: The ICTP RegCM3 and RegCNET, B. Amer. Meteor. Soc., 88, 1395-1409, 2007.

Paltridge, G. W. and C. M. R. Partt: The radiation processes in meteorology and climatology, translated by: Daren, L., Runheng, H., and Hai, L., Beijing, China, Science Press, 84-87, 1981.

Qiang, Z., Xiaoyan, C., and Guoan, W.: Observation and study of some key parameters of land surface process of Gobi in arid region, Adv. Atmos. Sci., 19, 1-14, 2002.

Qiang, Z. and Ronghui, H.: Parameters of land-surface processes for Gobi in Northwest China, Bound.-Lay. Meteorol., 110, 471-478, 2004.

Ranson, K. J., Irons, J. R., and Daughtry, C. S. T.: Surface albedo from bidirectional reflectance, Remote Sens. Environ., 35, 201-211, 1991.

Schaaf, C. B. and Coauthors: First operational SZA2 albedo nadir reflectance products from MODIS, Remote Sens. Environ., 83, 135-148, 2002.

Steiner, A. L., Pal, J. S., and Giorgi, F.: The coupling of the common land model (clm0) to a regional climate model (RegCM), Theor. Appl. Climal. 82, 225-243, 2005.

Tsvetsinskaya, E. A., Schaaf, C. B., Gao, F., Strahler, A. H., Dickinson, R. E., Zeng, X., and

20 Lucht, W.: Relating MODIS-derived surface albedo to soils and rock types over Northern Africa and the Arabian Peninsula, Geophys. Res. Lett., 29, 1353, doi:10.1029/2001 GL014096, 2002.

Tsvetsinskaya, E. A., Schaaf, C. B., and Gao, F.: Relating MODIS-derived surface albedo to soils and rock types over Northern Africa and the Arabian peninsula, Geophys. Res. Lett., 29(9), 1353, doi:10.1029/2001GL014096, 2002.

Wang, Z.: Using MODIS SZA2 and albedo data to evaluate global model land surface albedo, J. Hydro-meteor., 5: 3-14,2004.

Wang Z., Michael, B., Zeng, X. B., Dickinson, R. E., and Schaaf, C. B.: The solar zenith angle dependence of desert albedo, Geophys. Res. Lett., 32, L05403, doi:10.1029/2004GL021835, 2005.

Wang, S., Grant, R. F., Verseghy, D. L., Black, T. A.: Modeling plant carbon and nitrogen dynamics of a boreal aspen forest in CLASS-the Canadian Land Surface Scheme, Ecol. Model, 142, 135-142, 2001.

HESSD

6, 1651-1676, 2009

Improvement of surface albedo parameterization

Y. Bao and S. Lü

Title Page

Abstract

Introduction

Conclusions

References

Tables

Figures

14

$\rightarrow$

$\triangleleft$

Back

Close

Full Screen / Esc

Printer-friendly Version

Interactive Discussion 
Wang S., Grant, R. F., Verseghy, D. L., and Black, T. A.: Modeling carbon-coupled energy and water dynamics of a boreal aspen forest in a General Circulation Model Land Surface Scheme, Int. J. Climatol., 22, 1249-1265, 2002a.

Wang, S. and Davidson, A.: Impact of climate variations on surface albedo of a temperate grassland, Agric. Forest Meteor., 142, 133-142, 2007.

Wang, S., Grant, R. F., Verseghy, D. L., and Black, T. A.: Modeling carbon dynamics of boreal forest ecosystems using the Candadian Land Surface Scheme, Clim. Change, 55: 451-477, 2002b.

Wang, Z., Zeng, X., and Barlage, M.: Using MODIS BRDF and albedo data to evaluate global model land surface albedo, J. Hydrometeor., 5, 3-14, 2004.

Wang, Z., Zeng, X, and Barlage, M.: Moderate resolution imaging spectroradiometer bidirectional reflectance distribution function-based albedo parameterization for weather and climate models, J. Geography R., 12, 1-16, 2007.

Wen, X.-Y., Wang, S.-W., Zhu, J.-H., and David, W.: An Overview of China Climate Change over the 20th Century Using UK UEA/CRU High Resolution Grid Data, Chinese J. Atmos. Sci., 30, 894-904, 2006.

Wu, Aisheng and Qiang, Z.: Relationships between global surface albedo and solar elevation angle for several underlying surfaces in the HEIFE experimental area, Plateau Meteor., Chinese, 12, 147-155, 1993.

20 Yan, B., Lü, S., Yu, Z., Xianhong, M., and Shengpeng, Y.: Improvement of Surface Albedo Simulations over Arid Regions, Adv. Atmos. Sci., 25(3), 441-448, 2008.

Yan, B., Lü, S., Yinhuan, A., Shengpeng, Y., and Xuelong, C.: Improvement of Surface albedo Parameterization over Bare Soil on Surface Radiation and Thermal Process Modeling, Acta Energiae Solaris Sinica, Chinese, 28)5), 775-782, 2007.

Yan, B. and Lü, S.: Impacts of land parameters improvements on land modeling in arid region, Adv. Earth Sci., Chinese, 22, (Suppl.), 185-193, 2007.

Yongjiu, D., Xubin, Z., and Dickinson, R. E.: The common land model (CLM), B. Am. Meteor. Soc., 84(8), 1013-1023, 2003.

HESSD

$6,1651-1676,2009$

Improvement of surface albedo parameterization

Y. Bao and S. Lü

Title Page

Abstract

Introduction

Conclusions

References

Tables

Figures

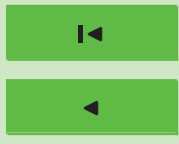

$\rightarrow 1$

Back

Close

Full Screen / Esc

Printer-friendly Version

Interactive Discussion 


\section{HESSD}

6, 1651-1676, 2009

\section{Improvement of surface albedo \\ parameterization}

Table 1. Regional JJA-averaged surface variables.

Y. Bao and S. Lü

\begin{tabular}{lcccccc}
\hline & \multicolumn{3}{c}{ East Asia } & \multicolumn{3}{c}{ Northwest China } \\
& RCM_ORI & RCM_SZA & CRU & RCM_ORI & RCM_SZA & CRU \\
\hline Albedo & 0.202 & 0.189 & & 0.264 & 0.253 & \\
Incident solar radiation $\left(\mathrm{Wm}^{-2}\right)$ & 233.439 & 242.866 & & 273.368 & 273.927 & \\
Surface absorbed radiation $\left(\mathrm{Wm}^{-2}\right)$ & 196.57 & 210.316 & & 208.282 & 214.186 & \\
Longwave cooling $\left(\mathrm{Wm}^{-2}\right)$ & 48.119 & 53.114 & & 108.290 & 113.138 & \\
Sensible heat flux $\left(\mathrm{Wm}^{-2}\right)$ & 39.378 & 44.007 & & 84.811 & 84.806 & \\
Latent heat flux $\left(\mathrm{Wm}^{-2}\right)$ & 101.269 & 103.855 & & 13.907 & 15.315 & \\
Surface air temperature (degree) & 24.166 & 25.368 & 25.387 & 23.046 & 23.157 & 21.970 \\
Daily maximal temperature (degree) & 25.738 & 26.653 & 29.638 & 24.560 & 24.900 & 29.291 \\
Daily minimal temperature (degree) & 23.648 & 24.146 & 21.172 & 21.536 & 21.811 & 14.671 \\
Precipitation (mm/day) & 5.330 & 5.466 & 5.869 & 0.417 & 1.037 & 1.040 \\
\hline
\end{tabular}

Title Page

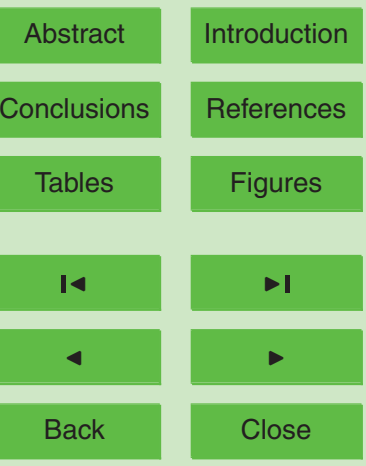

Full Screen / Esc

Printer-friendly Version

Interactive Discussion 


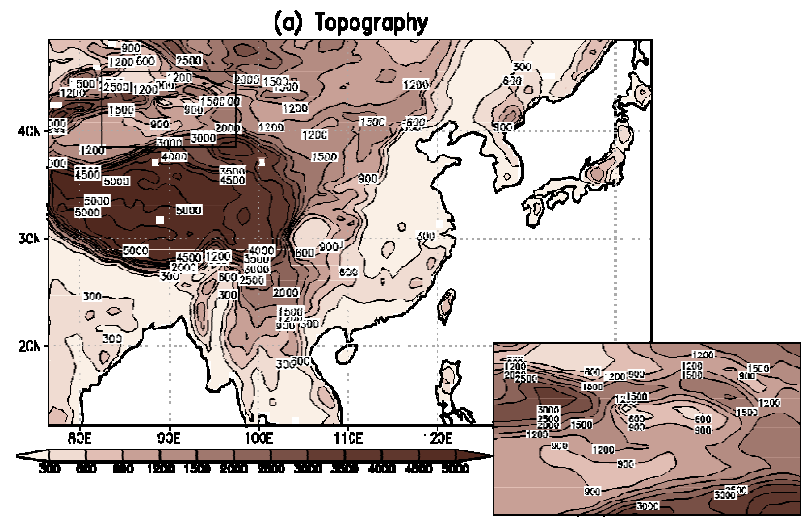

(b)LANDUSE

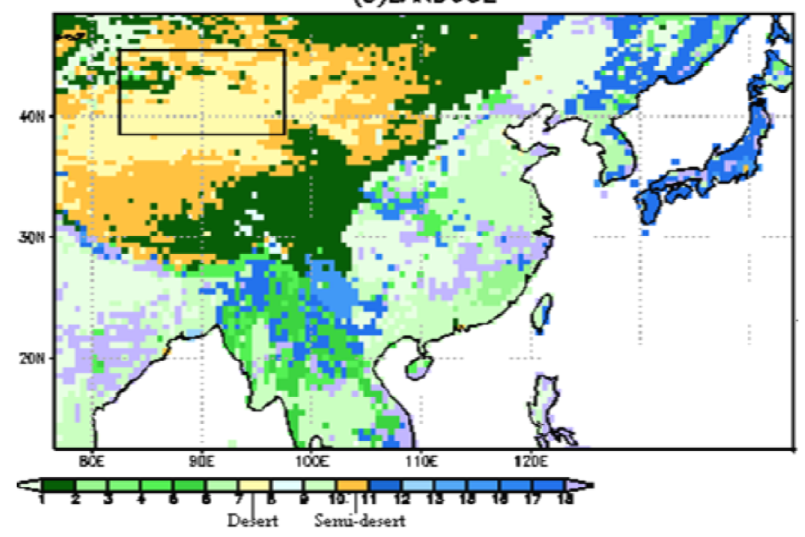

Fig. 1. Domain, topography and landuse (a) Mother and nested domain and topography (Units: meter) (b) landuse distribution.

\section{HESSD}

6, 1651-1676, 2009

Improvement of surface albedo parameterization

Y. Bao and S. Lü

Title Page

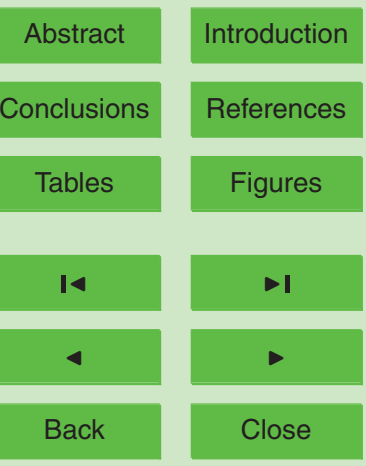

Full Screen / Esc

Printer-friendly Version

Interactive Discussion 


\section{HESSD}

(a) RCM_ORI

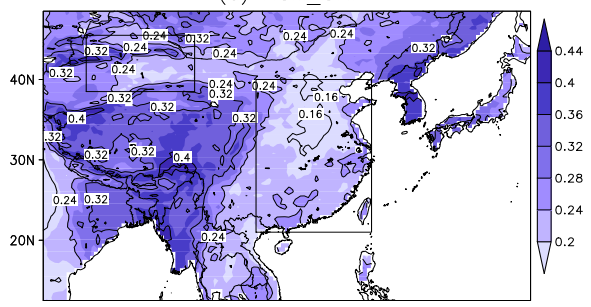

(b) RCM SZA

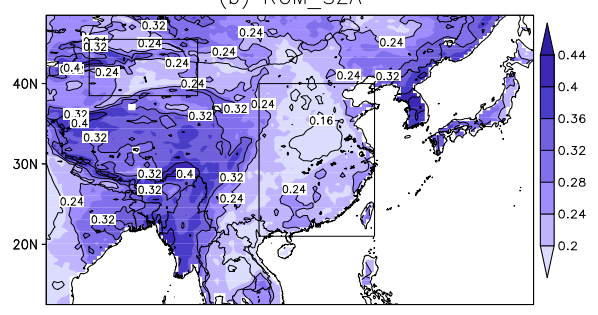

(c) Diff. RCM_SZA-RCM_ORI

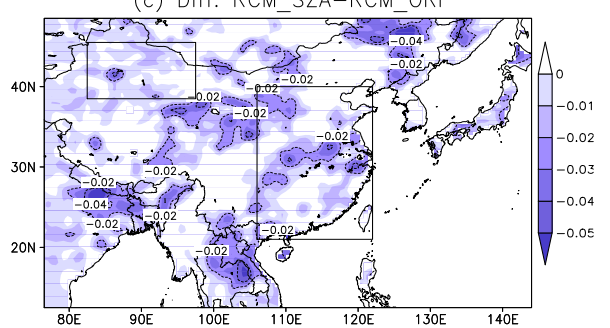

Fig. 2. JJA-averaged albedo distribution. (a) RCM_ORI; (b) RCM_SZA; (c) Difference between RCM_SZA and RCM_ORI (RCM_SZA-RCM_ORI).
6, 1651-1676, 2009

\section{Improvement of} surface albedo parameterization

Y. Bao and S. Lü

Title Page

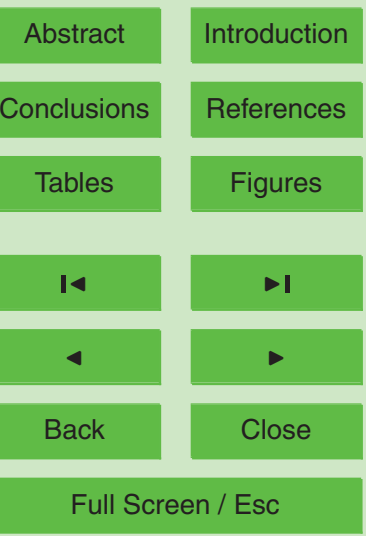

Printer-friendly Version

Interactive Discussion 


\section{HESSD}

6, 1651-1676, 2009
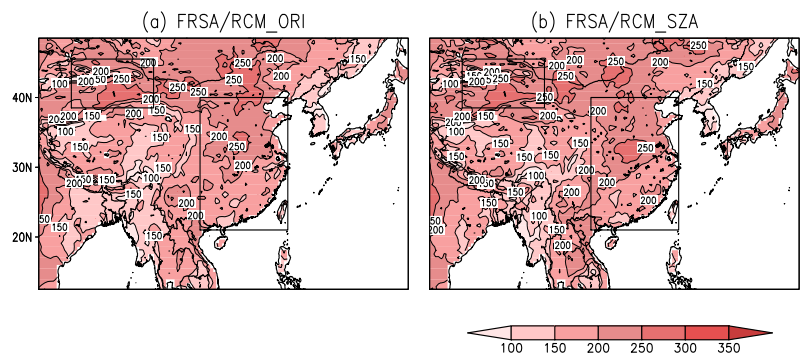

(d) FRLA/RCM OR
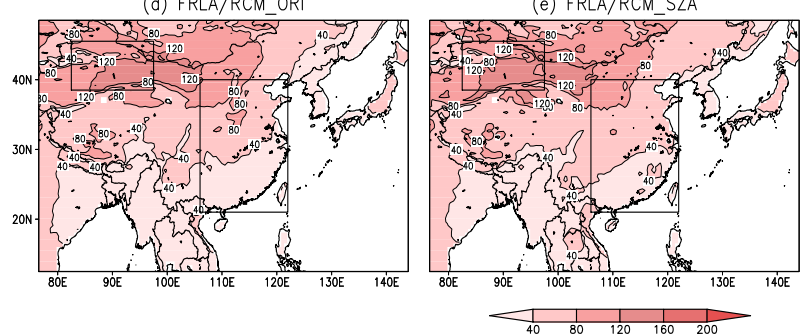

Fig. 3. JJA-averaged solar radiation absorbed by surface and longwave cooling radiation flux. (a) and (b) RCM_ORI; (c) and (d) RCM_SZA; (e) and (f) Difference between RCM_SZA and RCM_ORI (RCM_SZA-RCM_ORI). Panel on the left is solar radiation absorbed by surface, and panel on the right is longwave cooling radiation.

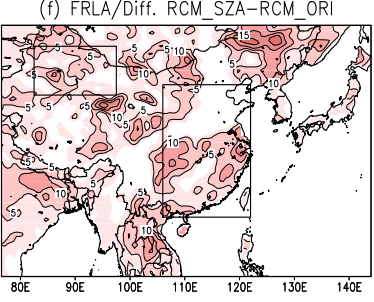

(c) FRSA/Diff. RCM_SZA-RCM_ORI

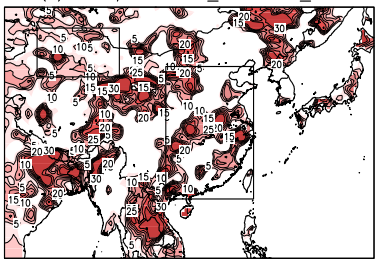

Improvement of surface albedo parameterization

Y. Bao and S. Lü

Title Page

Abstract

Introduction

Conclusions

References

Tables

Figures

14

4

Back

Close

\section{Full Screen / Esc}

Printer-friendly Version

Interactive Discussion 


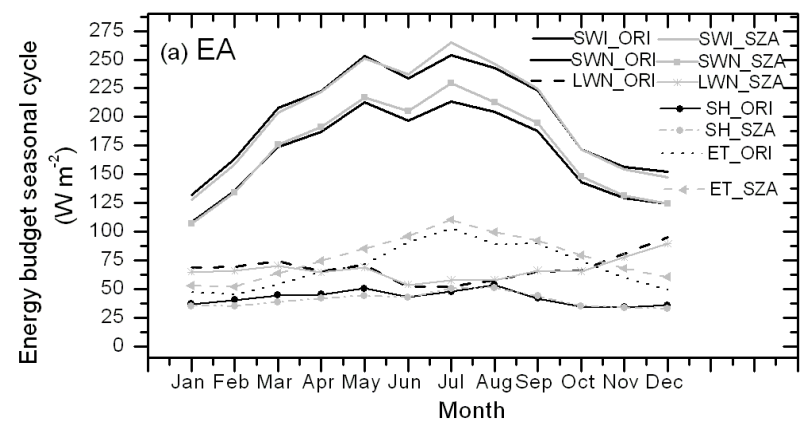

\section{HESSD}

6, 1651-1676, 2009

\section{Improvement of surface albedo parameterization}

Y. Bao and S. Lü

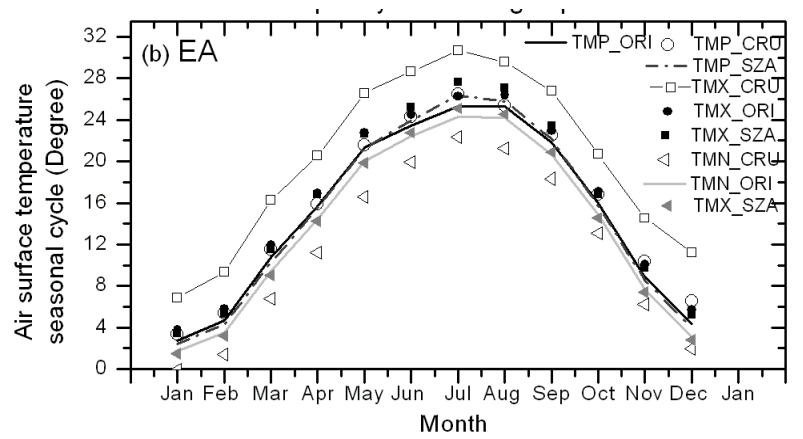

Title Page

Abstract

Introduction

Conclusions

References

Tables

Figures

14

4

Back

Close

\section{Full Screen / Esc}

Printer-friendly Version

Interactive Discussion 


\section{HESSD}

6, 1651-1676, 2009

(a) CRU
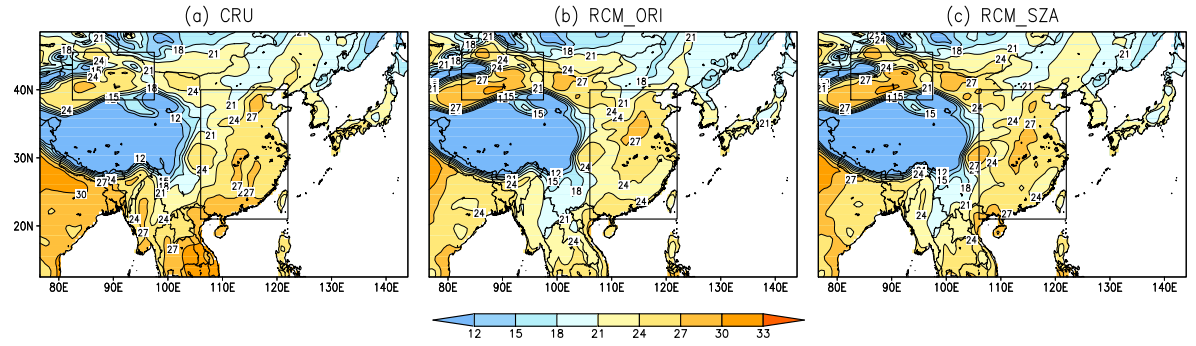

(e) Bias (RCM ORI-CRU)
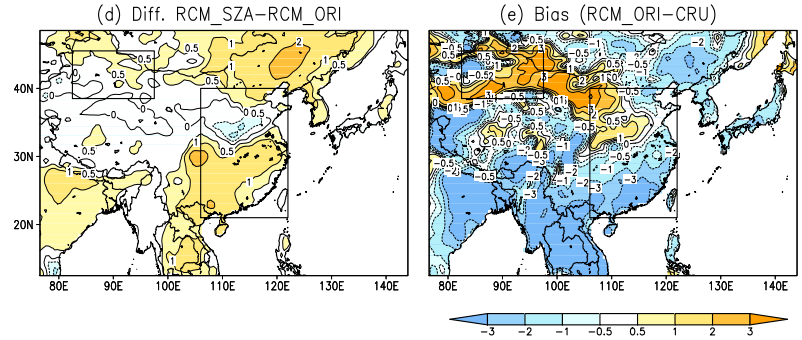

(f) Bias (RCM_SZA-CRU)

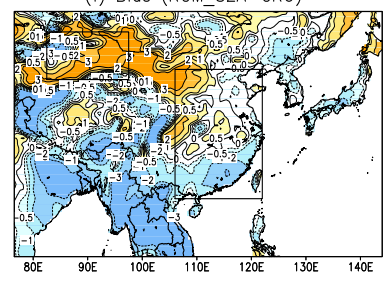

Fig. 5. Surface air temperature in JJA (Units: degree) (a) CRU (b) RCM_ORI (c) RCM_SZA (d) RCM_SZA-RCM_ORI (e) RCM_ORI-CRU (f) RCM_SZA-CRU.

\section{Improvement of surface albedo parameterization}

Y. Bao and S. Lü

Title Page

Abstract

Introduction

Conclusions

References

Tables

Figures
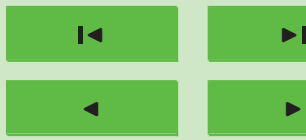

Back

Close

\section{Full Screen / Esc}

Printer-friendly Version

Interactive Discussion 


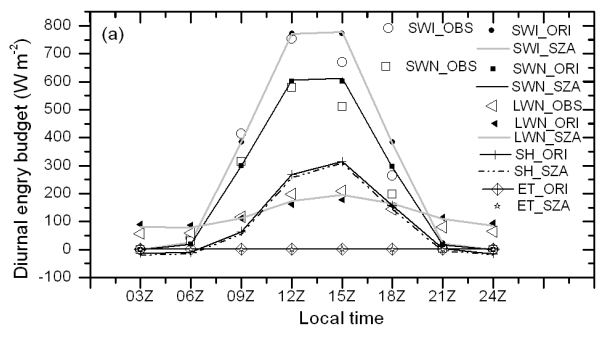

\section{HESSD}

6, 1651-1676, 2009

\section{Improvement of surface albedo \\ parameterization}

Y. Bao and S. Lü
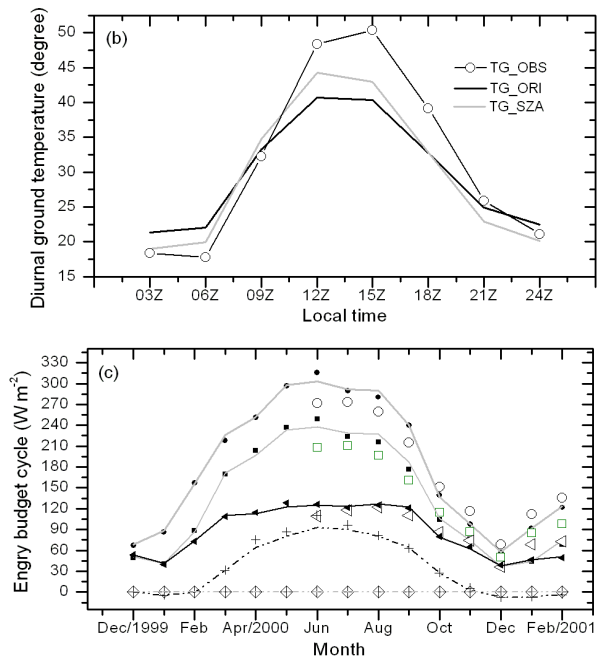

Title Page

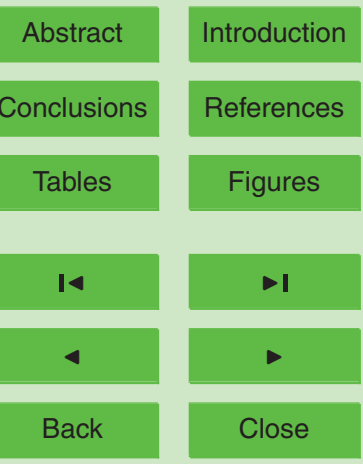

Full Screen / Esc

Fig. 6. Diurnal and seasonal energy cycle and air surface temperature at Dunhuang Gobi surface (a) Diurnal energy budget $\left(\mathrm{W} \mathrm{m}^{-2}\right)$ (b) Diurnal ground temperature (c) Seasonal energy budget $\left(\mathrm{W} \mathrm{m}^{-2}\right)$ (d) Seasonal ground temperature. 